\title{
Seasonal and interannual variability of the Canary Current*
}

\author{
E. NAVARRO-PÉREZ and E.D. BARTON \\ School of Ocean Sciences, University of Wales Bangor, Menai Bridge, LL59 5EY, Anglesey, Wales, United Kingdom.
}

\begin{abstract}
SUMMARY: Seasonal and interannual variability of the Canary Current on its passage through the Canary archipelago and between $20-35^{\circ} \mathrm{N}$ and $10-20^{\circ} \mathrm{N}$ are studied with long series of historical tide gauge, sea surface temperature and hydrographic data. The variability of winds is more seasonal in the north of the area, where they are weak and perpendicular to the coast in winter, than in the south, where winds are roughly parallel to shore all year though strongest in summer. Temperature and salinity data maps show a curved structure indicative of the subtropical gyre, which varies seasonally from North to South and from the open ocean to the coast. Dynamic height analyses show this seasonal variation of the gyre to depths of $200 \mathrm{~m}$ and indicate the existence of a meander-like diversion around the Canary Islands. The sea level in the Canary Islands also indicates a strong seasonal variation of the north Atlantic subtropical gyre. The southward geostrophic surface flow, derived from sea surface slope, was strongest during spring and summer at the eastern islands while it was strongest in winter at the outermost islands. The spatially averaged flow between the innermost and outermost islands shows the strongest southward flow in winter. Interannual variation of the flow between these islands, investigated during two periods, 1950-1956 and 1960-1973, reveals a mainly southward flow, although several show a northward tendency. The maximum equatorward velocity of the current in both periods is around $5 \mathrm{~cm} \mathrm{~s}^{-1}$, indicating a weak current.
\end{abstract}

Key words: seasonal and interannual varibility, sea level, Canary Current, subtropical gyre.

\section{INTRODUCTION}

The region of study, defined by $20-35^{\circ} \mathrm{N}$ and 10 $20^{\circ} \mathrm{W}$, includes the Canary Islands archipelago situated at around $28^{\circ} \mathrm{N}$. Their geographical situation and its proximity to the Sahara would be expected to make it desertic. However, the influence of the Trade winds and the cool water Canary Current greatly moderate the climate and produce major oceanographic structures.

The bathymetry of the islands is typically abrupt, with only a narrow shelf or platform present, producing near-shore conditions similar to the open ocean. The archipelago constitutes a barrier to the

\footnotetext{
*Received November 22, 1999. Accepted July 7, 2000
}

passage of the Canary Current as it flows towards the equator, which produces meandering and eddies in the flow downstream. Other important oceanographic characteristics in this region originate from upwelling off the African coast.

The importance of defining the seasonal variation of the region lies in its relation to the upwelling phenomenon, which depends on the Trade Winds and also varies with the latitude. South of the region the upwelling occurs in winter and spring seasons. Between $20-25^{\circ} \mathrm{N}$ the upwelling occurs all year, with maximum intensity during spring and autumn. North of $25^{\circ} \mathrm{N}$ the upwelling occurs in summer and early autumn (Mittelstaedt, 1991; Van Camp et al., 1991; Hagen et al., 1996, Barton et al., 1988). 


\section{DATA AND METHODS}

The historical databases used to define the seasonal and interannual variability of the region are the Comprehensive Ocean-Atmosphere Data Set (COADS), National Oceanographic Data Centre (NODC) hydrographic data and tide gauge data from the Permanent Service for Mean Sea Level (PSMSL) and from the Instituto Español de Oceanografía (IEO).

The COADS database is made up of observations taken since 1854 from merchant ships of many countries. These data cover observations of nearsurface winds and sea surface temperature (SST). These data are summarised statistically for each month of the year, using cells of 1 degree latitude by 1 degree longitude. The monthly maps produced represent the average of all data included in each cell between 1854 and 1990 .

The NODC data are selected from Nansen station files. These data are stored in ASCII form and are separated in subdirectories relative to a quadrant number. Each quadrant is divided into several files that contain data from different sub-regions. In contrast with the COADS data set, the NODC data are a compilation of many individual scientific cruises carried out in the area.

The COADS historical hydrographic data are represented in monthly mean sea surface temperature (SST) and wind maps (Fig .1). The database from the NODC is too sparse to represent as monthly mean maps, so the data are represented as autumn/winter and spring/summer maps (Fig. 2). Dynamic height relative to $500 \mathrm{dbar}$ is calculated from the NODC data to investigate the variation of the geostrophic flow at different depths, but because many profiles are incomplete the dynamic height estimates are even sparser. For this reason, the resultant maps are smoothed to 2 by 2 and 3 by 3 degree cells (Fig. 3).

Historical tide gauge data from different islands of the Canaries archipelago are used to investigate the seasonal variation of the Canary Current in its passage through the archipelago. The database con-
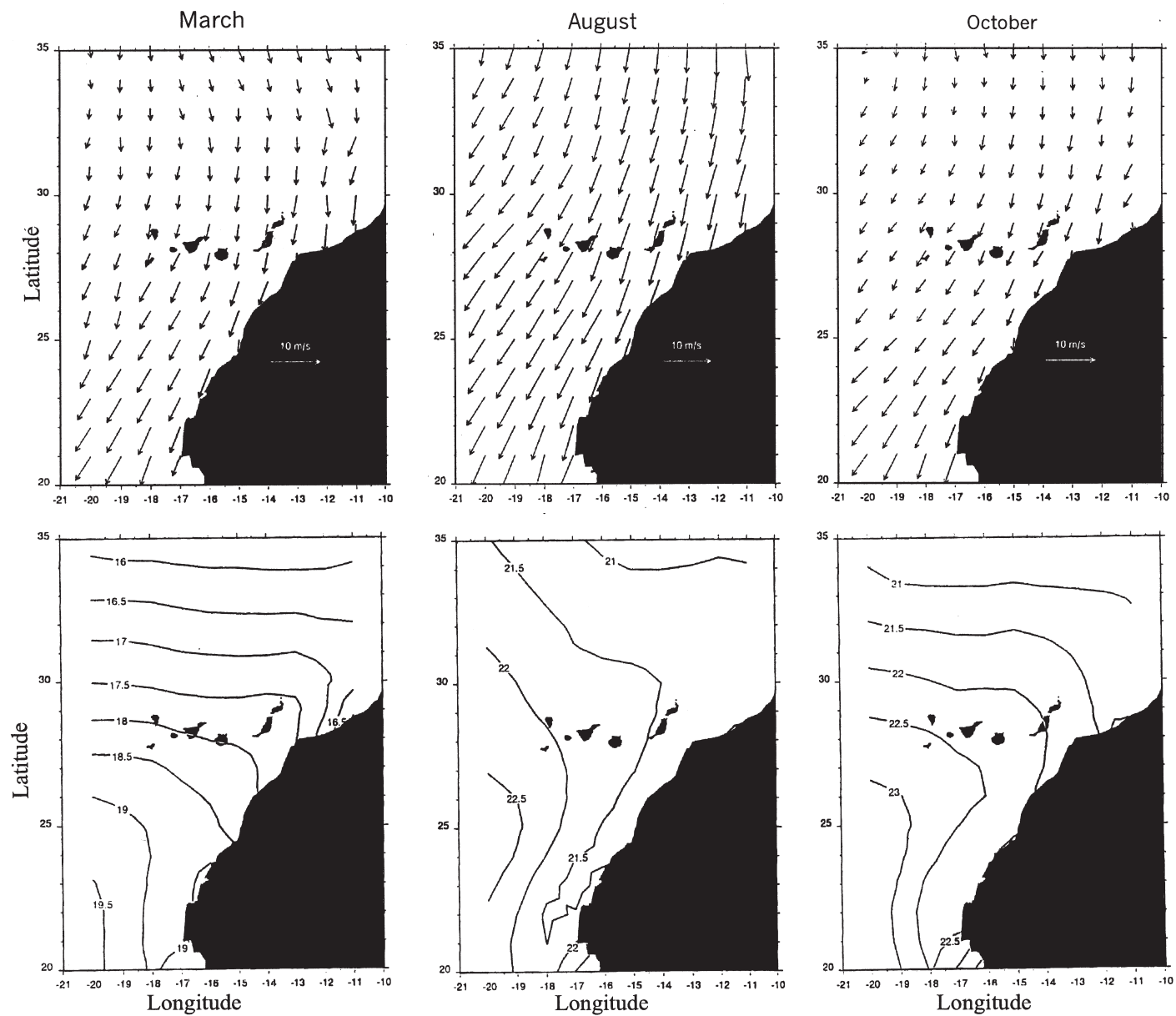

FIG. 1. - Maps of monthly mean surface wind vectors and surface temperatures for March, August and October based on the COADS historical data base. 

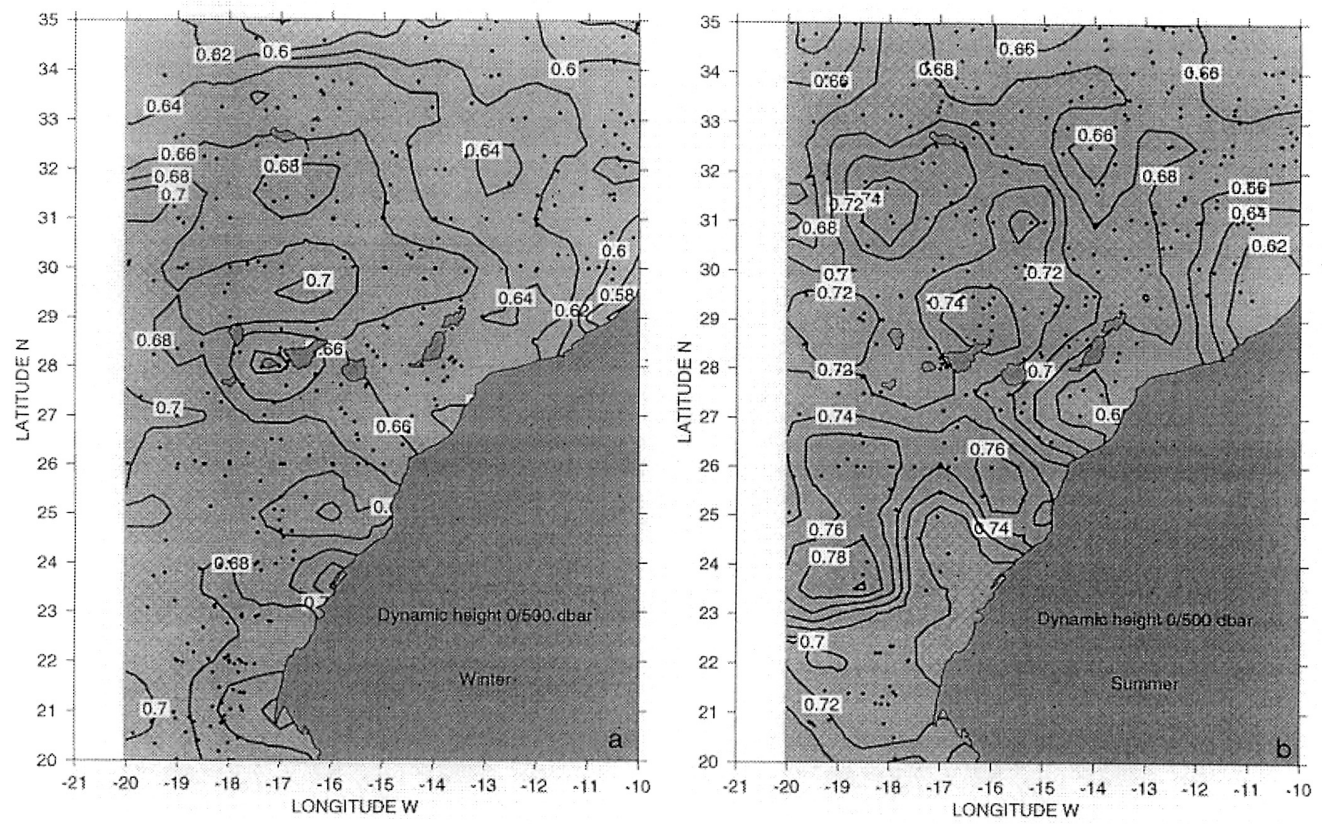

FIG. 2. - Dynamic height (dyn m) at 0/500 dbar in half year maps (a,b). The flow seemed to be diverted around the Canary Islands with a meander form.
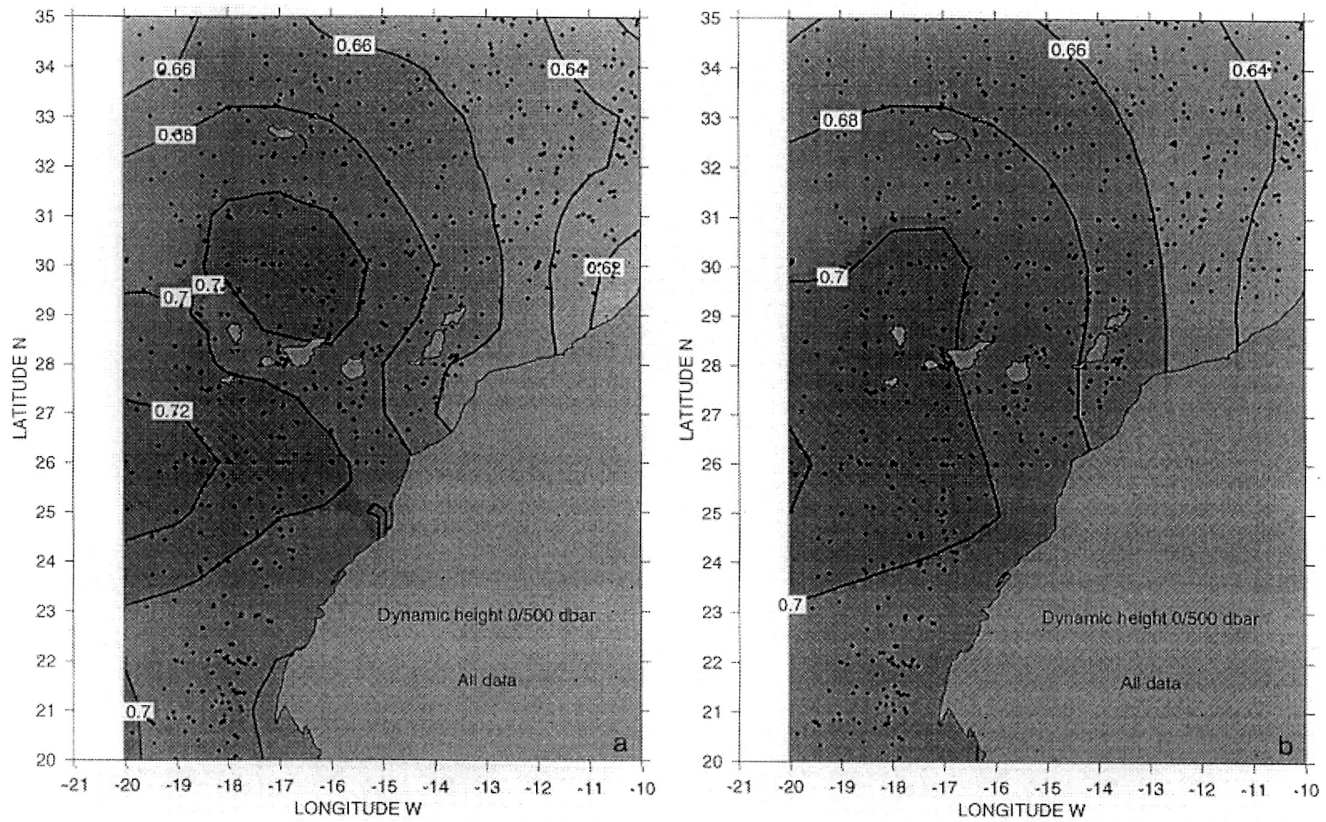

FIG. 3. - Dynamic height (dyn $\mathrm{m}$ ) maps at $0 / 500$ dbar with all data representation. The effect of smoothing is seen by calculating weighted averages over areas of (a) $2 \times 2$ and (b) $3 \times 3$ degrees.

sists of monthly data from five tide gauges and daily data from only three tide gauge stations. The monthly data are in short time series with gaps at some stations, whereas the daily data are in long time series. Consequently, a combination of monthly and daily data is used to analyze the longest time series available of around 12 years.

In the monthly data, two stations, La Palma and Lanzarote, are situated at the extremes of the archi- pelago and the other two, Tenerife and Las Palmas, in the middle. Two tide gauges are located in the same port in Tenerife. These two stations are used to check the data quality during two common periods, 1927-1935 and 1941-1946. The result shows an excellent correlation between them. Daily data are available for only three stations, La Palma, Las Palmas and Arrecife. The Las Palmas tide gauge revealed strong trends between the 1970s and 1990s, 
so these periods are rejected for analysis. A common period of monthly data at all stations between 19501956 is studied. Subsequently, a combination of daily data sets for the period 1960-1972 is analyzed using two stations, La Palma and Arrecife, located at the ends of the archipelago.

The tide gauges are leveled by reference to the calculated dynamic heights. By setting the mean tide gauge level to the mean dynamic height calculated close to each site, an absolute height difference between each pair of gauges is obtained, allowing absolute current values to be estimated. In the analysis the stations are ordered so that positive height differences correspond to southward flow.

With the leveled data it is possible to obtain geostrophic velocity relative to a common subsurface reference level from the height differences between gauges. Geostrophic velocity of the current $c=g \Delta h /(f L)$ is calculated, where $\Delta h$ is the height difference between two stations, $g$ the acceleration due to gravity, $f$ the Coriolis parameter, and $L$ the distance between stations.

The analysis of the tide gauge data incorporated atmospheric pressure data to correct for the inverse barometer effect, whereby increases and decreases in atmospheric pressure depress and elevate the sea level respectively. The meteorological data are obtained from the COADS database for the latitude and longitude closest to each tide gauge station. It is found that in the Canaries archipelago atmospheric pressure does not have a significant effect on currents because the pressure is almost the same across the archipelago, so any change in the sea level slope is inappreciable.

\section{RESULTS}

\section{Seasonal variation}

The COADS wind data show the large scale variation of the Trade Winds. Monthly average winds are generally southwestward throughout the year. From April to September they are strong $\left(6 \mathrm{~m} \mathrm{~s}^{-1}\right)$, with maximum values in July and August $\left(>10 \mathrm{~m} \mathrm{~s}^{-1}\right)$. Generally, winds are roughly parallel to the African coast south of $28^{\circ} \mathrm{N}$. North of this latitude they have a strong onshore component and therefore will not produce such a strong upwelling as further south. Although in winter the winds of the region are weaker, the monthly averages are always directed equatorward, indicating conditions favorable for coastal upwelling all year around.
The sea surface temperature (SST) revealed a typical curved pattern where the isotherms open out seaward to the west away from the coast (Fig. 1). Particularly in the Northwest the isotherms have a zonal tendency, but as they approach the coast they become more perpendicular to shore. In the central region they are typically aligned more parallel to the coast and in the south they turn offshore. This pattern in the isotherms reflects the structure of the subtropical gyre circulation and the predominance of coastal upwelling over the central part of the region, where coastal temperatures are cooler than those of the open ocean.

Near the Canary Islands the monthly mean SST varies from roughly $18^{\circ} \mathrm{C}$ in January to $22.5^{\circ} \mathrm{C}$ in August. However, the temperature difference between the two extremes of the archipelago is only $0.5^{\circ} \mathrm{C}$, the warmer water being found in the west.

As expected, the temperature and salinity maps from the NODC data show the same major characteristics as the COADS data (Fig. 4). In the north the contours are basically zonal but turn southwards as they approach the coast and become more aligned with the coast in the centre of the region before turning offshore in the south. The overall curved structure of the temperature and salinity maps ranges seasonally from north to south and from open ocean to coast. In winter and autumn the structure is displaced to the north and toward the open ocean, while in summer and spring the structure moves to the south and closer to the coast. Another feature of the NODC maps, as distinct from COADS, is the frequent occurrence of isolated maximum and minimum values and the irregular appearance of the isolines. This is due to the low number of available data points, which means that individual cruises can affect the overall pattern greatly. The interpretation of the maps is based on their large-scale features rather than on their detailed structure.

Seasonal representation of the dynamic height at $0 \mathrm{~m}$ relative to $500 \mathrm{~m}$ reveals that the current flowing equatorward parallel to the African coast is diverted around the Canary Islands in a meander form as if the archipelago presents a barrier to the flow. The database for these maps is sparse (Fig. 2), and some structures that are apparent in the maps could be artifacts. Nevertheless, a similar meanderlike flow has been referred to previously by Fedoseev (1970) and Mittelstaedt (1991). Recently, Laiz et al. (2001) discuss a similar circulation feature from a theoretical point of view. 

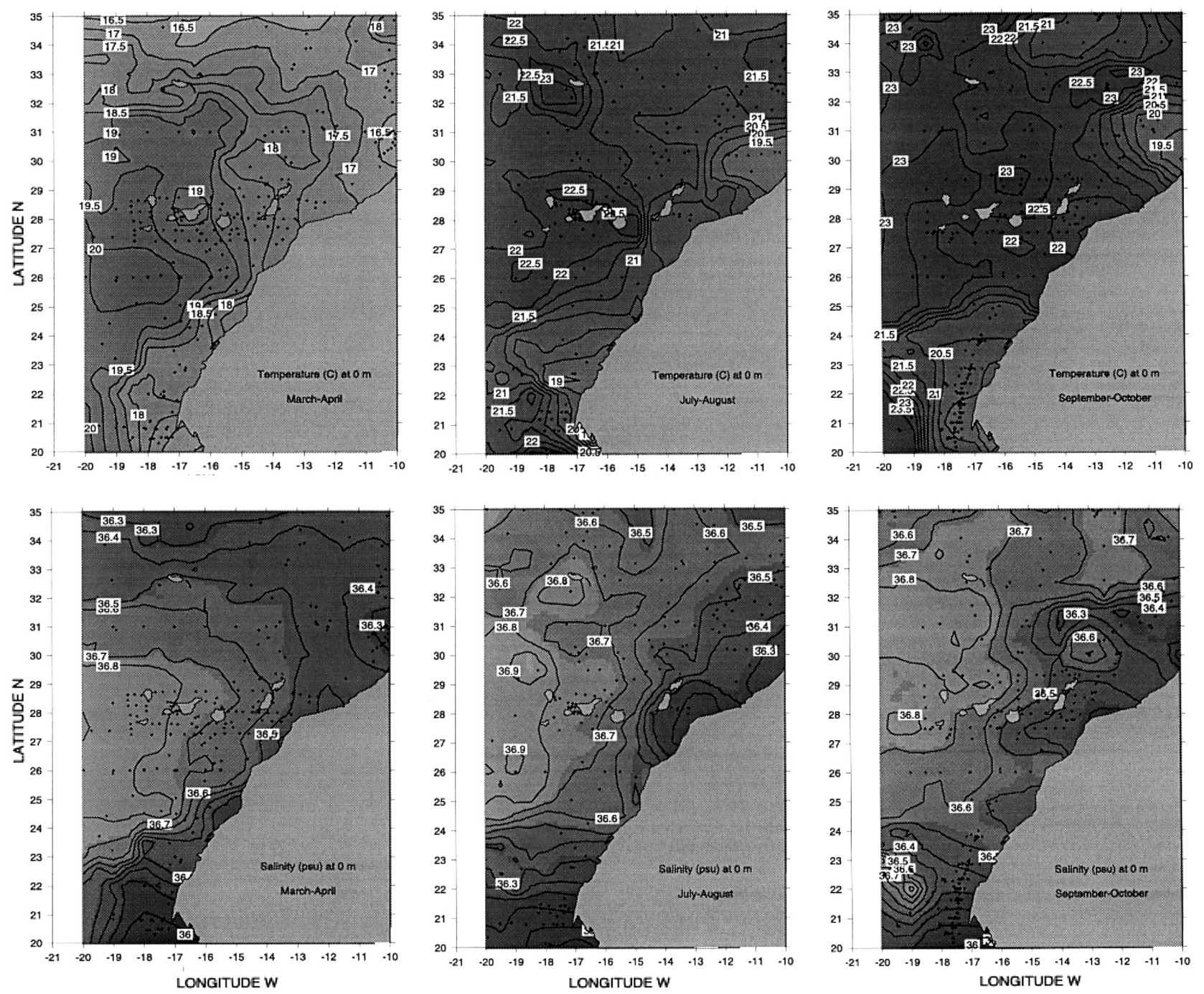

FIG. 4. - Maps of bi-monthly mean sea surface temperature and salinity for March-April, July-August and September-October on archived NODC hydrographic data.

A possible cause of this wide anti clockwise meander around the Canary Islands could be topographic steering around the depth contours of the area. However, the channels between the islands are generally deeper than $2000 \mathrm{~m}$ (between the islands and Africa the channel is approximately $1500 \mathrm{~m}$ deep) and the flow beneath $500 \mathrm{~m}$ is weak, so the influence of the bottom on the current is expected to be minimal. It must be remembered, however, that the mean flows discussed here are very weak $(2 \mathrm{~cm}$ $\mathrm{s}^{-1}$ ) and so the topographic steering of this background flow will generally be obscured by larger amplitude mesoscale variability which dominates the instantaneous flow.

The seasonal variation of the daily sea level data from the tide gauge sites in the period 1960-72 reveals an annual cycle at all sites with a maximum occurring in summer and autumn (Fig. 5). The max-

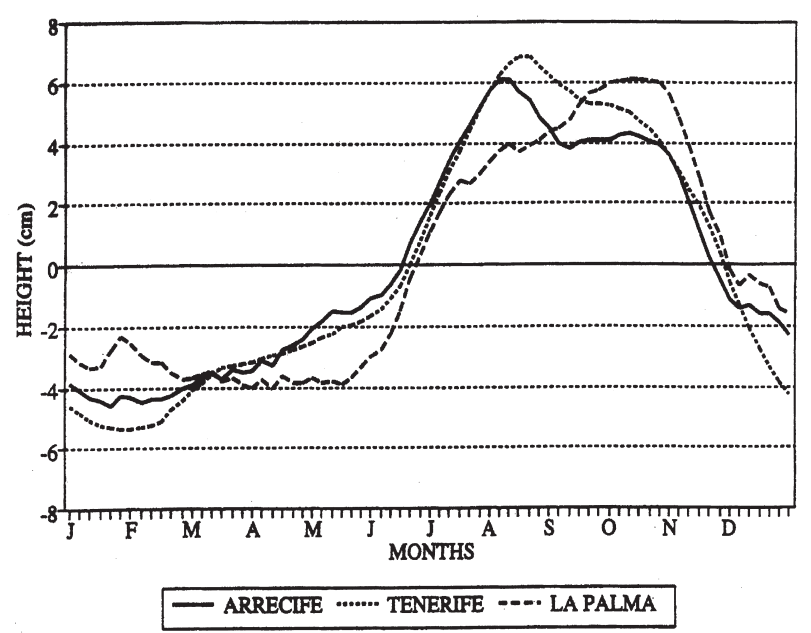

FIG. 5. - Seasonal variation for Arrecife, Tenerife and La Palma stations for period 1960-1972. The tide gauges revealed an annual cycle with maximum during summer and autumn. 
imum appears first in Arrecife, closest to the African coast, at the beginning of August, then in Tenerife at the end of the month, and finally in La Palma, the station furthest offshore, in late September-October. Similar results were obtained for the 1950-1956 Daily series, though all peaks occurred about a month earlier.

The variation of the current depended on the position of the stations. The annual mean sea level differences between La Palma and Tenerife, located further offshore, show a southward signal in winter but a northward tendency in summer, whereas the differences between Tenerife and Arrecife, located near the African coast, indicated a southward flow all year, which is strongest in August and September. The position of the subtropical gyre affects the way in which the currents vary from the coast to the open ocean during the year. The broad picture of strongest equatorward flow in summer closer to the coast and in winter further offshore is in agreement with the results of Stramma and Siedler (1988), and Siedler et al. (1985) show current meter observations of northward flow during part of the year at a mooring northwest of La Palma.

The average geostrophic surface current speeds in the area, calculated from the sea surface height differences between the extreme islands, are found to be weak, less than $5 \pm 0.4 \mathrm{~cm} \mathrm{~s}^{-1}$ (Fig. 6). Higher and more variable values are obtained with the differences calculated with more closely spaced sea level stations in the middle of the archipelago. As indicated above, the position of the Canary Current core may shift offshore and onshore during the year.

The steric contribution to sea level, i.e. the density variation introduced by temperature and salinity

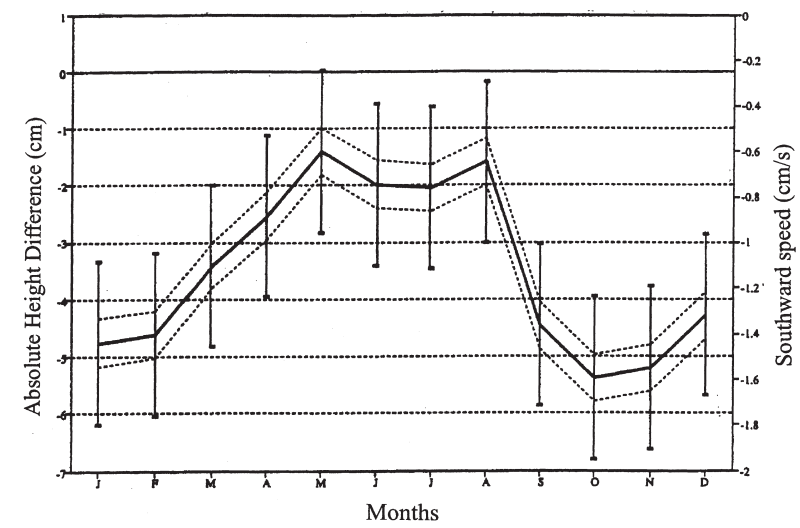

FIG. 6. - Seasonal variation of the height difference and normal component of the current speed between La Palma and Arrecife with the atmospheric pressure and the hydrographic reference level included. Period 1960-1972. The dashed lines indicate the variation of the mean errors of average value while the vertical line represents the variation of the standard deviation. variations but dominated by temperature, is analyzed as a possible cause of the summer peak which appears in the seasonal variation of the tide gauge stations. The hydrographic data are too sparse to investigate the variation of steric height close to each individual tide gauge site for any difference in timing of the summer peak from east to west. Instead, monthly values are determined by averaging the values from diagonals of $400 \mathrm{~km}$ length parallel to the African coast at different points across the archipelago. These averaged monthly sea surface heights are superimposed on the tide gauge data. The results indicate the strong similarity between the two data series, in which the steric effect signal makes a mean contribution of $75 \%$ to the seasonal signal of the tide gauge stations. The large percentage of sea level variation due to the steric effect arises here largely from the seasonal heating cycle, as elsewhere in the subtropics (Patullo et al., 1955). Although the heat exchange may vary slightly across the islands due to the surface temperature and wind gradients, it is probably not of great importance. Furthermore, the surface flow is determined only by the zonal differences in sea surface height.

\section{Interannual variation}

The interannual variation shows a mean southward flow, although several years show periods of northward flow (Fig. 8). The maximum speed reached for these northward episodes of flow is $4 \mathrm{~cm}$ $\mathrm{s}^{-1}$, while that for southward flows reaches higher values. This apparent occurrence of the northward flow from the view of the general circulation is not

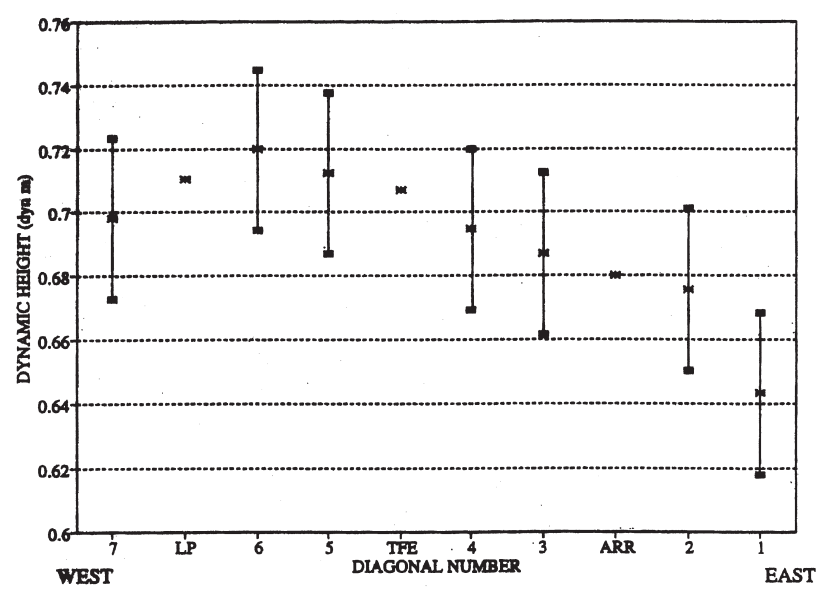

FIG. 7. - Mean dynamic height (dyn m) referring to $0 / 500$ dbar calculated from the hydrographic data and the tide gauge stations. Vertical lines represent the standard deviation. 

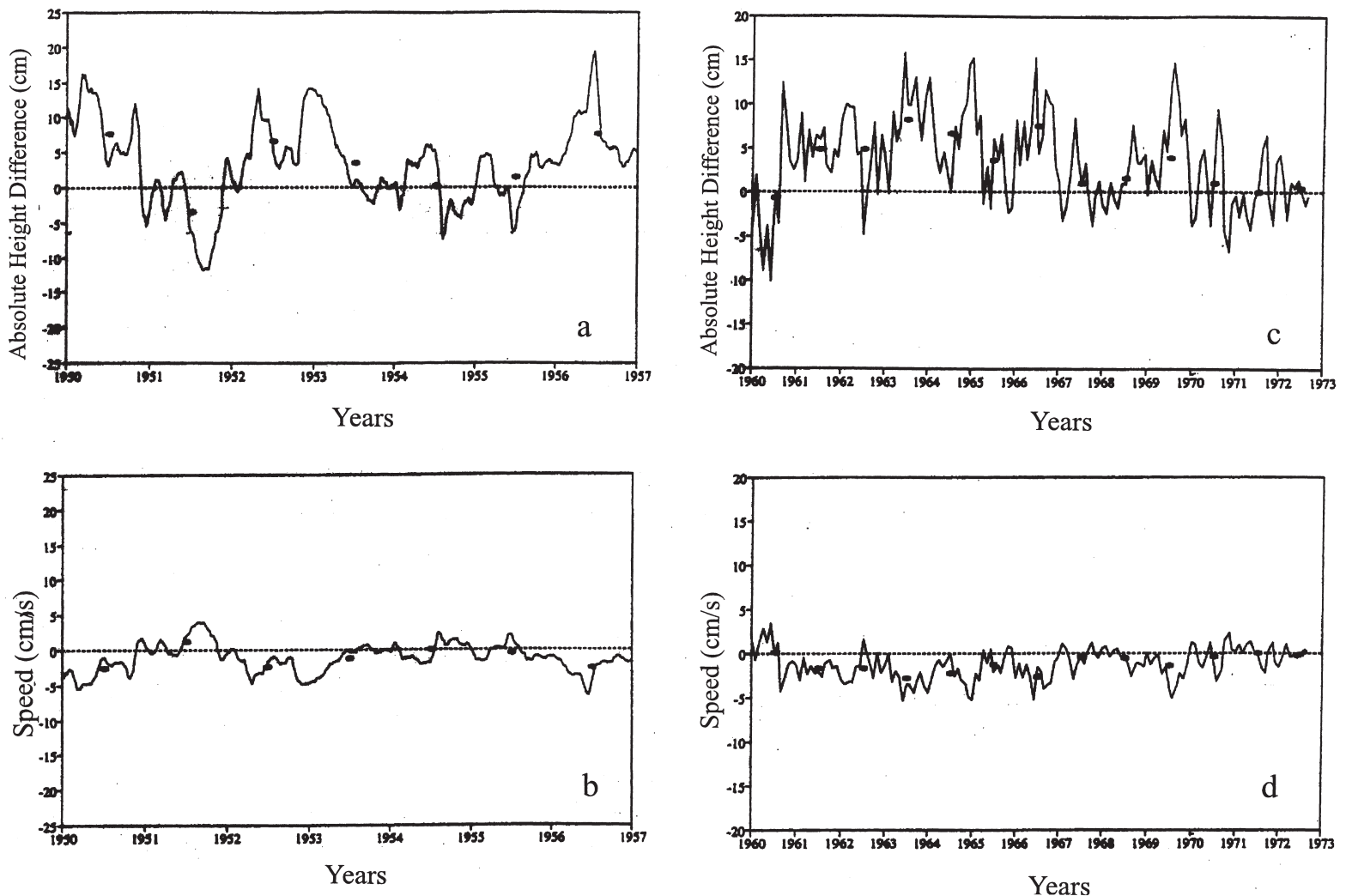

FIG. 8. - Interannual variation of the height difference $(\mathrm{cm})$ and Normal component of the current speed $\left(\mathrm{cm} \mathrm{s}^{-1}\right)$ between La Palma and Arrecife in the periods 1950-1957 (a,b) and 1960-1972 (c,d). The reference level at 0/500 dbars was included in the analysis. Annual averages are indicated by the black dots.

readily acceptable. Nevertheless, Stramma and Siedler (1988) found northward flow south of the Canary Islands in long term autumn mean geostrophic transport, although it did not have a high statistical significance. They also observed a northward flow in spring and autumn at $165 \mathrm{~m}$ depth on a mooring situated south of the Canaries. Despite these reports, the existence of northward flow persisting for almost a year is still a puzzling result.

The causes of the apparent northward flow can be sought in any of the three main factors that affect the estimated current results: the reference level, the atmospheric pressure, and the sea level records. The reference level is based on all available hydrographic data. Sea surface profiles indicate a maximum surface elevation inshore of La Palma station with surface height decreasing further offshore (Fig. 7). However, this result might be unrealistic because there were few NODC data in that area. Reference to the large scale-maps of the dynamic topography shows that the maximum elevation is a relatively localized feature which disappears in smoothed maps, leading to a uniform rise in sea level in the offshore direction. The smoothed sea surface height at La Palma is only a few centimeters less, which would be insufficient to change the direction of the current, although it would reduce the strength of the northward flow. Indeed, to reduce the maximum calculated northward flow (around $4 \mathrm{~cm} \mathrm{~s}^{-1}$ ) to southward flow, the sea level at La Palma would have to be increased by $10 \mathrm{~cm}$. In this analysis, a constant reference level at $500 \mathrm{dbar}$ has been assumed because this was the maximum depth of most NODC data. However, spatially varying reference depths might be more realistic, but across the width of the archipelago the depth differences would be small. Use of a deeper local reference level could not change the mean dynamic topography sufficiently to reduce northward flow to zero. It can be concluded that the reference level is not the main cause of the northward flow obtained in the results.

The atmospheric pressure is another factor that affects the calculated currents. The pressure series from the COADS data are based on a few observations per month and some gaps in the series have been filled by interpolation. However, the inclusion or exclusion of this series makes very little difference to the current calculations since pressure varies insignificantly across the archipelago and the cause of the northwards flow is not due to this 
parameter.

The last factor that influences the current estimate is the sea level data set. The original series were clearly subject to abrupt changes, strong trends and data gaps. The series periods used in the calculations are specifically selected to exclude the worst data. Comparison between two long series recorded simultaneously in Tenerife indicated a good correlation in the data, giving some confidence in the quality of the results. The Las Palmas station is suspect, probably due to progressive large scale construction in the harbor, and is therefore rejected in the analysis. The La Palma and Arrecife series used for overall calculation of spatially averaged flows is compared over two periods, 1950-56 and 1960-72 (Fig. 8a,b), when data appear reliable, and the results are similar for both periods. However, the possibility that La Palma, Arrecife or both series contained some error cannot be excluded completely.

It seems clear from the sea level results that the seasonal variation is well defined and provides strong confirmation of earlier work on seasonal change of the subtropical gyre. With the interannual variation, a conservative conclusion is that significant changes occur from year to year in the mean flow through the Canaries. If it is accepted that the La Palma and Arrecife series are reliable, then it must be concluded that the flow is generally equatorward at speeds of up to $5 \mathrm{~cm} \mathrm{~s}^{-1}$, but that extended periods of northward flow occur in the current spatially averaged across the islands. Finally, it can be recognized that the spatially averaged currents are relatively weak, so intense localized northward flows could be responsible for the overall result.

Mean geostrophic transport calculated from the historical hydrographic data has a value of $1.4 \mathrm{~Sv}$. This transport has been referenced to $500 \mathrm{~m}$ depth. This agrees with the results obtained by Stramma (1984), who showed that the geostrophic transport close to the African coast and Canary Islands was only $1 \mathrm{~Sv}$ above $200 \mathrm{~m}$. Furthermore, he concluded that most of the transport is carried in the upper 200 $\mathrm{m}$, in agreement with the results presented here.

\section{DISCUSSION}

The data used in this work have been examined from the overall area to a long term average. The large-scale picture indicates a smoothly varying background with a number of anomalies or localised features.

The large-scale structure visible in sea surface temperature, salinity and dynamic height data was associated with the variability of the subtropical gyre in the eastern Atlantic. It has been shown that the shape of the eastern part of the subtropical gyre off northwest Africa varies as its position migrates from north to south annually. The seasonal variation of the gyre from north to south and from open ocean to coast has been reported by Stramma and Siedler (1988). They showed on the very large scale a seasonal variation of the subtropical gyre in which the centre was located at $29^{\circ} \mathrm{N}$ in winter and at $30^{\circ} \mathrm{N}$ in spring, while it shifts south to $27^{\circ} \mathrm{N}$ in summer and back northwards to $29^{\circ} \mathrm{N}$ in autumn. The variation of the subtropical gyre influences water down to 200 $\mathrm{m}$ depth, below which the signal is inappreciable (Navarro-Perez, 1996).

The sea level observations reflect the variation down to smaller spatial scales of the separation between islands on a time scale of months. Here the main result of the seasonal variation of the gyre was also seen, with an indication that the strongest flow is found nearer to the African shore in summer. The net alongshore flow through the Canary Islands is shown to be on average weakly southward as expected, but during periods of several months the flow is northward against the sense of the gyre. While it is possible that this apparently anomalous result arises from poor data quality, the agreement between two separate periods of study and with a number of observations by other workers suggest that it is probably realistic. It could of course result from strong localized flows dominating a weak general equatorward flow.

The large scale observations show the complexity of processes in the region. The reason for the many small anomalies in the large scale distributions becomes clear when it is considered that very strong flows and associated patterns of temperature (e.g. Navarro-Perez and Barton, 1998) and salinity can greatly influence spatial averages made up from relatively few scattered observations. Similarly, the disturbance effect of the islands on the background flow is known to produce intense local effects (Barton et al., 1999). Can mesoscale structure directly affect observations of sea level at the islands? The answer must be positive because of the strong dynamic height signal associated with the localised intense flows. Of course, if smaller scale structures like filaments frequently extend to the inner islands, then their influence is reflected in the mean patterns 
and their effect is included in the overall average flow. Perhaps a more interesting observation is that the background large-scale flow is quite weak at only a few centimetres per second while the instantaneous flows are one to two orders of magnitude greater. However, over even the small area of the filament study reported by Navarro-Perez and Barton (1998) the average flow was similar to the mean large-scale flow in both direction and magnitude.

\section{CONCLUSIONS}

The seasonal variation has an important influence on the Canary Current flow. Overall patterns of temperature salinity and dynamic height represent the subtropical gyre which moves seasonally from the north to the south and from west to east. The Canaries archipelago constitutes a barrier to the flow in its equatorward path, causing it to meander around the archipelago. It is observed that the influence of this meander form reaches depths of less than $200 \mathrm{~m}$.

The tide gauge data indicate a seasonal variation of sea level between islands of the Canaries archipelago with maximum values in summer. These peaks appear earlier in the islands near the African coast due to the variation of the Subtropical Gyre: in Arrecife the maximum is reached in August while in La Palma it is reached in October. When spatially averaged between the extreme islands of the Canaries archipelago for the two periods 1950-1956 and 1960-1972, the mean flow of the Canary Current shows a weak mean southward flow of 1 to 2 $\mathrm{cm} \mathrm{s}^{-1}$. The strongest equatorward spatially averaged flow occurs in winter, when the subtropical gyre is located further north and further offshore. The main variability of the Canary Current occurs in the uppermost $200 \mathrm{~m}$. The interannual variation of sea level indicates a mainly southward flow with some exceptional years of northward flow. The variation in the mean flow is $\pm 5 \mathrm{~cm} \mathrm{~s}^{-1}$, with a transport across the archipelago of $1.4 \mathrm{~Sv}$.

\section{REFERENCES}

Barton, E.D. - 1987. Meanders, eddies and intrusions in the thermohaline front off northwest Africa. Oceanol. Acta., 10(3): 267-283.

Barton, E.D., J. Arístegui, P. Tett, M. Cantón, J. García-Braun, S. Hernández-León, L. Nykjaer, C. Almeida, J. Almunia, S. Ballesteros, G. Basterretxea, J. Escánez, L. García-Weill, A. Hernández-Guerra, F. López-Laatzen, R. Molina, M.F. Montero, E. Navarro-Pérez, J.M. Rodríguez, K. van Lenning, H. Vélez and K. Wild. - 1998. The transition zone of the Canary Current upwelling region. Prog. Oceanogr., 41: 445-504.

Fedoseev, A. - 1970. Geostrophic circulation of Surface Waters on the Shelf of North - West Africa. Rapp. Proc. Verb. Reun. Cons. Inst. Expl. Mer., 159: 30-37.

Hagen, E., C. Zülicke and R. Feistel. - 1996. Near-surface structures in the Cape Ghir filament off Morocco. Oceanol. Acta, 19(6): 577-598.

Hughes, P. and E.D. Barton. - 1974. Stratification and water mass structure in the upwelling area off northwest Africa in April/May 1969. Deep-Sea Res., 21: 611-628.

Mittelstaedt, E. - 1991. The ocean boundary along the Northwest African coast circulation and Oceanographic properties at the sea surface. Prog. Oceanogr., 26: 307-355 pp.

Navarro-Pérez, E. H.S. Vélez-Muñoz and K.A. Wild - 1994. BIO Hespérides cruise report: hydrographic fields. European Coastal Transition Zone Islas Canarias MAST Project Report 0031-16, UCNW Bangor, 150 pp.

Navarro-Pérez, E. and E.D. Barton. - 1995. BIO Hespérides Cruise 9308 cruise report: Acoustic Doppler Current Fields. European Coastal Transition Zone Islas Canarias MAST Project Report 0031-19, UCNW, Bangor 71 pp.

Navarro-Pérez, E. and E.D. Barton. - 1998. The physical structure of upwelling filament off the North-West african coast during August 1993. S. Afr. J. Mar. Sci., 19: 61-73.

Patullo, J., W. Munk, R. Revelle and E. Strong. - 1955. The seasonal oscillation in sea level. J. Mar. Res., 14: 88-155.

Siedler, G., W. Zenk and W.J. Emery. - 1985. Strong current events related to a Subtropical front in the Northeast Atlantic. J. Phys. Oceanogr., 15: 885-897.

Stramma, L. - 1984. Geostrophic transport in the Warm Water Sphere of the eastern subtropical North Atlantic. J. Mar. Res., 42: 537-558.

Stramma, L. and G. Siedler. - 1988. Seasonal Changes in the North Atlantic Subtropical Gyre. J. Geophys. Res., 93(C7): 81118118.

Van Camp, L., E. Mittelstaedt and P. Schlittenhardt. - 1991. Upwelling and boundary circulation off Northwest Africa as depicted by infrared and visible satellite observations. Prog. 
